\title{
Antagonism of Ang-Tie2 and Dll4-Notch signaling has opposing effects on tumor endothelial cell proliferation, evidenced by a new flow cytometry method
}

\author{
Marc Payton ${ }^{1}$, Toni Jun², William Wayne, Dongyin Yu, Raffi Manoukian, Grace Chung ${ }^{1}$, Nancy Zhang ${ }^{4}$, \\ Ji-Rong Sun ${ }^{1}$, Paula Kaplan-Lefko ${ }^{5}$, Sheila Scully ${ }^{6}$, Gwyneth Van ${ }^{6}$, Robert Radinsky ${ }^{1}$, Richard Kendall, \\ Jonathan Oliner ${ }^{1}$ and Angela Coxon ${ }^{1}$
}

Sustained angiogenesis is essential for tumor growth as it provides the tumor with a network of blood vessels that supply both oxygen and essential nutrients. Limiting tumor-associated angiogenesis is a proven strategy for the treatment of human cancer. To date, the rapid detection and quantitation of tumor-associated endothelial cell (TAEC) proliferation has been challenging, largely due to the low frequency of endothelial cells (ECS) within the tumor microenvironment. In this report, we address this problem using a new multiparametric flow cytometry method capable of rapid and precise quantitation of proliferation by measuring bromodeoxyuridine (BrdUrd) uptake in mouse TAECs from established human tumor xenografts. We determined the basal proliferation labeling index of TAECs in two human tumor xenografts representing two distinct histologies, COLO 205 (colorectal cancer) and U-87 (glioblastoma). We then investigated the effects of two large-molecule antiangiogenic agents targeting different biochemical pathways. Blocking angiopoietinTie2 signaling with the peptide-Fc fusion protein, trebananib (AMG 386), inhibited proliferation of TAECs, whereas blocking DII4-Notch signaling with an anti-DII4-specific antibody induced hyperproliferation of TAECs. These pharmacodynamic studies highlight the sensitivity and utility of this flow cytometry-based method and demonstrate the value of this assay to rapidly assess the in vivo proliferative effects of angiogenesis-targeted agents on both the tumor and the associated vasculature.

Laboratory Investigation (2014) 94, 1296-1308; doi:10.1038/labinvest.2014.116; published online 22 September 2014

In healthy human adult tissues, endothelial cells (ECs) are in a non-proliferative differentiated state, with the exception of female reproductive organs. In contrast, under pathological conditions such as cancer, ECs proliferate to support tumor growth. Sustained vascular stimuli represent a hallmark of cancer and are necessary to support new vessel formation required for tumor growth and metastasis. ${ }^{1-3}$ Vascular endothelial growth factor (VEGF)-A and its receptor are essential regulators of angiogenesis, whereby VEGF stimulates sprouting and proliferation of ECs. ${ }^{4}$ A number of large- and smallmolecule drugs that target the VEGF-signaling pathway are effective at inhibiting tumor angiogenesis and have been approved for the treatment of several types of human cancer. ${ }^{4,5}$

Additional signaling pathways are also required for tumor angiogenesis, including the angiopoietin-Tie2 and delta-like ligand 4 (Dll4)-Notch axes, which are both known to cooperate with VEGF to promote tumor angiogenesis. ${ }^{5,6}$ Trebananib (AMG 386), an investigational peptide-Fc fusion protein that prevents binding of angiopoietins 1 and 2 (ang- 1 and ang-2) to their receptor Tie2, inhibits angiogenesis, growth of tumor xenografts, and proliferation of tumor endothelial cells. ${ }^{7-12}$ In contrast, several studies have shown that administration of an anti-Dll4-specific antibody stimulates the proliferation of endothelial tip cells and increases vascular density in human tumor xenografts. ${ }^{13-17}$ However, this is believed to contribute to tumor starvation and suppression of tumor growth as inhibition of Dll4-Notch signaling results in the formation of nonfunctional immature vessels leading to poor tumor perfusion.

Previous reports have described methods to isolate, culture, and analyze ECs and TAECs from both normal and diseased

\footnotetext{
${ }^{1}$ Department of Oncology Research, Amgen Inc., Thousand Oaks, CA, USA; ${ }^{2}$ Department of Cell Biology, AnaptysBio Inc. San Diego, CA, USA; ${ }^{3}$ Department of Flow Cytometry, Cell Signaling Technology Inc., Danvers, MA, USA; ${ }^{4}$ Department of Companion Diagnostic Product Development, Dako Inc., Carpinteria, CA, USA;

${ }^{5}$ Department of Medicine, Hematology/Oncology, UCLA, Los Angeles, CA, USA and ${ }^{6}$ Department of Pathology, Amgen Inc., Thousand Oaks, CA, USA Correspondence: M Payton, Principal Scientist, Department of Oncology Research, Amgen Inc., One Amgen Center, Thousand Oaks, CA 91320, USA.

E-mail: mpayton@amgen.com

Received 8 January 2014; revised 20 August 2014; accepted 22 August 2014
} 
tissues using both imaging- and flow cytometry-based techniques. ${ }^{5,18-26}$ These methods typically use one or more antibodies directed against EC-specific markers such as CD31 (also known as PECAM1), which is highly expressed on the extracellular surface of ECs. In this report, we present a complete description and further improvements of a flow cytometric method used to establish a proliferation labeling index for TAECs contained in dissociated human tumor xenografts. ${ }^{7}$ By combining anti-CD31 and anti-CD45 (leukocyte marker) antibody staining, we successfully distinguish TAECs (stain $\mathrm{CD} 31^{\text {high }} / \mathrm{CD} 45^{\text {low }}$ ) from tumor-associated macrophages (stain $\mathrm{CD} 31^{\text {low }} / \mathrm{CD} 45^{\text {high }}$ ). We show that TAECs represent only a minor fraction $(\leq 2 \%)$ of the total cell population in COLO 205 and U-87 tumor xenografts. Cellular uptake and DNA incorporation of a synthetic nucleoside analog of thymidine, BrdUrd, is used to enumerate the percentage of actively proliferating cells. Using this technique, we establish the mean basal proliferation labeling indices for TAECs from COLO 205 and U-87 tumor xenografts. We demonstrate that sorted $\mathrm{CD} 31^{\text {high }} / \mathrm{CD} 45^{\text {neg }}$ cells from COLO 205 tumor xenografts maintain an EC phenotype in culture: specifically, CD31 expression and uptake of fluorescently labeled acetylated low-density lipoprotein (Ac-LDL). ${ }^{22}$ Further refinement of our methods allows us to simultaneously monitor proliferation of both pure TAEC and U-87-GFP tumor cell populations from the same xenograft sample. We characterize the in vivo effects of two antiangiogenic agents on TAEC proliferation, highlighting the usefulness of our method for cancer drug discovery. Notably, our studies demonstrate that trebananib and an anti-Dll4 neutralizing antibody have distinct and opposing effects on TAEC proliferation in human tumor xenografts.

\section{MATERIALS AND METHODS Cell Lines}

Cell lines were obtained from the American Type Culture Collection (ATCC, Manassas, VA) unless otherwise specified. Cell lines were grown under recommended conditions. U-87 MG cells obtained from ATCC are referred to as U-87 cells. Lentiviral vector-mediated gene expression of green fluorescent protein (GFP) was used to establish U-87-GFP cells at Amgen Inc. (Thousand Oaks, CA). Human umbilical vein endothelial cells (HUVEC) and EGM-2 culture media were obtained from Lonza (Walkersville, MD). Sorted CD $31^{\text {high }}$ / $\mathrm{CD} 45^{\text {neg }}$ cells were isolated from established COLO 205 tumor xenograft tissue and grown on collagen-1-coated Falcon plates (Thermo Fisher Scientific, Waltham, MA) in EGM-2 culture media.

\section{Human Tumor Xenograft Models and Large Molecule Reagents}

All experimental procedures were conducted in accordance with Institutional Animal Care and Use Committee and US Department of Agriculture regulations. The laboratory housing the cages met the standards of the Association for
Assessment and Accreditation of Laboratory Animal Care specifications. Eight- to ten-week-old female athymic nude mice were housed in sterilized filter-capped cages and maintained under aseptic and pathogen-free conditions. All animals were purchased from Charles River Laboratories (Wilmington, MA). Tumor cell suspensions $\left(2 \times 10^{6} \mathrm{COLO}\right.$ 205 tumor cells in $0.2 \mathrm{ml}$ RPMI (Life Technologies, Carlsbad, $\mathrm{CA}$ ) and matrigel (BD Biosciences, San Jose, CA) at 2-to-1 volume of matrigel-to-cells; $5 \times 10^{6} \mathrm{U}-87$ or U-87-GFP cells in $0.1 \mathrm{ml}$ of MEM high glucose media (Life Technologies)) were implanted subcutaneously (s.c.) in the flank of mice. Trebananib (ang-1 and -2 -neutralizing peptibody), ${ }^{7-11}$ an anti-Dll4 monoclonal antibody, human IgG, and human Fc were made by Amgen. Single-dose treatment with trebananib, an anti-Dll4 antibody, or vehicle (PBS (Life Technologies), human IgG or $\mathrm{Fc}$ ) was performed with well-established tumors (volume $\sim 500 \mathrm{~mm}^{3}$ ). Large-molecule agents or vehicle were administered by intraperitoneal (i.p.) or s.c. injection.

\section{Tissue Collection and Dissociation}

Eighteen hours before tissue collection, mice were implanted s.c. with osmotic minipumps (Alza, Model 2001D, Cupertino, CA) with a flow rate of $8 \mu \mathrm{l}$ per hour containing $3.3 \mathrm{mg} / \mathrm{ml}$ BrdUrd (Life Technologies). Heparin (150 units, VWR, Radnor, PA) was administered i.p. to mice $10 \mathrm{~min}$ before tissue collection. Tissue samples were immediately minced and incubated in $10 \mathrm{ml}$ of digestion medium (Hank's Balanced Salt Solution (Life Technologies), 2\% BSA (ICN, Costa Mesa, CA), $0.2 \mathrm{mg} / \mathrm{ml}$ collagenase IV and $0.1 \mathrm{mg} / \mathrm{ml}$ of collagenase XI (Sigma-Aldrich, St. Louis, MO), 2.5 units $/ \mathrm{ml}$ DNase I (Roche Diagnostics, Indianapolis, IN), and $0.5 \times$ dispase (Life Technologies)) and incubated at $37^{\circ} \mathrm{C}$ for $30 \mathrm{~min}$, using an inverted $50 \mathrm{ml}$ conical tube (Falcon) with a sterile small magnetic stir bar under continuous mixing on a stir plate. Tumor suspensions were further processed using an automated mechanical dissociation system (gentleMACS, Miltenyi, Auburn, CA). The resulting cell suspension was centrifuged at 2000 r.p.m. for $5 \mathrm{~min}$. All subsequent centrifugations were performed at this speed and for this duration. Cell pellets were washed with $5 \mathrm{ml}$ of room temperature Versene (Life Technologies). The final single-cell suspension was passed through a 100-micron mesh screen (Falcon), centrifuged, resuspended in cell surface staining buffer (CSSB; 1\% BSA in $1 \times \mathrm{PBS}$ ) and stored on ice before staining. The spleen tissue samples were fixed in $90 \%$ ice-cold methanol (Sigma-Aldrich) and processed for BrdUrd analysis as previously described. ${ }^{27}$

\section{Antibodies for Flow Cytometry}

Rat anti-mouse antibodies were obtained from BD Biosciences. Rat anti-mouse antibodies include anti-CD45-FITC (cat 557355), anti-CD45-PerCP (cat 561047), anti-CD31-PE (cat 553373), anti-Flk-1-PE (cat 555308), anti-IgG2b IsotypeFITC (cat 553988), anti-IgG2a Isotype-PerCP (cat 552991), 
and anti-IgG2a Isotype-PE (cat 553930). Rat anti-mouse anti-CD45-PerCP antibody was substituted for anti-CD45FITC for studies using a U-87-GFP tumor xenograft model. Mouse anti-BrdUrd-alexa-647 antibodies (cat A21305, cat B35140) were obtained from Life Technologies.

\section{Cell Surface, BrdUrd, and DNA Staining}

Approximately $1 \times 10^{6}$ cells were stained with an anti-CD45 and anti-CD31 antibody cocktail $(2.5 \mu \mathrm{g} / \mathrm{ml}$ each antibody) in CSSB on ice for $1 \mathrm{~h}$. Cells were then centrifuged at 2000 r.p.m. for 5 min and washed twice with cold CSSB. Cells were fixed in $100 \mu \mathrm{l}$ BD Cytofix/Cytoperm buffer (BD Biosciences) and incubated on ice for $30 \mathrm{~min}$. Cells were washed in Perm/Wash buffer (BD Biosciences) and retreated with $100 \mu \mathrm{l}$ Cytofix/Cytoperm buffer for an additional $5 \mathrm{~min}$. Cells were resuspended in $100 \mu \mathrm{l}$ DNase I (BD Biosciences) at a concentration of $30 \mu \mathrm{g} / \mathrm{well}$ at $37^{\circ} \mathrm{C}$ for $1 \mathrm{~h}$, washed and resuspended in $100 \mu \mathrm{l}$ Perm/Wash buffer containing antiBrdUrd-alexa-647 antibody at a final concentration of $3 \mu \mathrm{g} / \mathrm{ml}$ and incubated at room temperature for $1 \mathrm{~h}$. We omitted DNase I treatment to serve as a BrdUrd negative control in one sample. Cells were washed twice using Perm/Wash buffer,

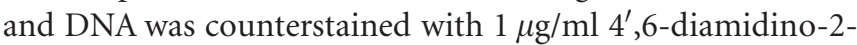
phenylindole, dihydrochloride (DAPI, Life Technologies) or $50 \mu \mathrm{l} / \mathrm{ml}$ 7-amino-actinomycin D (7-AAD, BD Biosciences) at room temperature for $15 \mathrm{~min}$. Cells were filtered through a 35 -micron mesh screen and stored at $4{ }^{\circ} \mathrm{C}$ until analysis by flow cytometry.

\section{Flow Cytometry Analysis}

Cells were analyzed using either FACSCalibur or LSRII flow cytometers (BD Biosciences) running CellQuest and Diva software, respectively. Automated (LSRII only, HTS) or manual sample loading was used for data acquisition. Photomultiplier tube (PMT) and compensation settings (FITC vs $\mathrm{PE}$ and PerCP $v s \mathrm{PE}$ ) were optimized using single-color antiCD45-FITC, anti-CD45-PerCP, anti-CD31-PE, and corresponding isotype control antibodies. As setup controls, we supplemented dissociated COLO 205 tumor xenograft cells with mouse lung cells to aid in setting the compensation for the $\mathrm{CD} 31^{\text {high }} / \mathrm{CD} 45^{\text {neg }}$ cell population. We applied region gates based on cell size and DNA content to remove cell debris and clumps and to enrich for cells with intact DNA content (mixture of tumor (aneuploidy) and mouse (euploid) cells). A region gate for $\mathrm{CD} 31^{\text {high }} \mathrm{CD} 45^{\text {neg }}$ cell population was applied to demarcate the pure TAECs. For the U-87-GFP tumor xenografts, we applied additional region gates on the GFP-positive and negative cell populations. Proliferation labeling indices were determined by applying region gates on BrdUrd-positive events for either CD $31^{\text {high }} / \mathrm{CD} 45^{\text {neg }}$ or U-87GFP high cell populations.

\section{Cell Surface Staining of Cultured Cells}

Mouse angiosarcoma SVR cells and sorted COLO 205 tumor xenograft TAECs were stained with $2.5 \mu \mathrm{g} / \mathrm{ml}$ of each rat anti-mouse antibody (anti-CD31-PE, anti-Flk-1-PE and anti-IgG2a-PE isotype control) in cell surface staining buffer on ice for $1 \mathrm{~h}$. The cells were centrifuged at 2000 r.p.m. for $5 \mathrm{~min}$ and washed twice with cold cell surface staining buffer. Cells were stained with $50 \mu \mathrm{l} / \mathrm{ml}$ 7-AAD on ice for $15 \mathrm{~min}$ to identify nonviable cells. Cells were filtered through a 35-micron mesh screen and analyzed by flow cytometry (FACSCalibur).

\section{Acetylated Low-Density Lipoprotein (Ac-LDL) Uptake Assay}

Ac-LDL and LDL labeled with fluorescent lipophilic dye Dil (1, $1^{\prime}$-dioctadecyl-3,3,3', $3^{\prime}$-tetramethyl-indocarbocyanine perchlorate) were purchased from Biomedical Technologies (Stoughton, MA). Live cells were incubated with $10 \mu \mathrm{g} / \mathrm{ml}$ of DiI-Ac-LDL or Dil-LDL (negative control) in complete growth media at $37^{\circ} \mathrm{C}$. After $4 \mathrm{~h}$, the cells were washed in label-free medium, fixed in $3.7 \%$ formaldehyde (SigmaAldrich) for $10 \mathrm{~min}$, and then washed with PBS. Fixed cells were stained with DNA dye (DAPI) before imaging. Representative images of sorted-TAECs were captured by laser scanning cytometry (iCyte, Thorlabs, Newton, NJ). HUVECs, sorted TAECs, SVR cells, and NIH-3T3 fibroblast cells were evaluated for DiI-Ac-LDL uptake by flow cytometry (FACSCalibur).

\section{CD31 and BrdUrd Immunohistochemistry (IHC)}

U-87-GFP tumor xenograft tissues were collected and fixed by immersion in zinc formalin, and embedded in paraffin. Tumor sections $(4 \mu \mathrm{m})$ were deparaffinized, hydrated in distilled water, pretreated with DIVA antigen retrieval buffer (Biocare Medical, Concord, CA), and then blocked with CAS-Block (Invitrogen). Sections were double labeled in series using rat monoclonal antibodies against anti-BrdUrd (cat OBT0030; Serotec, Raleigh, NC) and anti-CD31 (cat DIA310; Dianova, Hamburg, Germany). In brief, sections were first incubated with an anti-BrdUrd antibody at 1:500 antibody diluent (50 mM TRIS HCL pH7.6, $1 \%$ BSA) for $45 \mathrm{~min}$ at room temperature and then rinsed in TBS. Detection of BrdUrd was performed using a biotinylated rabbit anti-rat IgG antibody at 1:500 dilution (cat BA4001; Vector Labs, Burlingame, CA) for $25 \mathrm{~min}$ at room temperature. Sections were quenched with $3 \%$ hydrogen peroxide and labeled with horseradish peroxidase using ABC-HRP (Vector Labs). Reaction sites were visualized with 3,3'-diaminobenzidine (DAB; DAKO, Carpinteria, CA) as the first chromogen. Sections were treated with $2 \mathrm{~N} \mathrm{HCl}$ and thoroughly rinsed before incubation with an anti-CD31 antibody at 1:50 dilution for $60 \mathrm{~min}$ at room temperature. CD31 immunoreactivity was detected using biotinylated rabbit anti-rat IgG (Vector Labs) and labeled with alkaline phosphatase using ABC-AP (Vector Labs). Reaction sites were visualized with AP-Blue (Vector Labs) as the second chromogen. Sections were counterstained with hematoxylin. Slides were analyzed using a Scanscope XT slide scanner using 
$\times 20$ scanning magnification running ImageScope software (Aperio Technologies, Vista, CA).

\section{DNA Content Analysis}

Dissociated U-87 tumor xenografts were stained with antiCD45-FITC and anti-CD31-PE antibodies, fixed, and then counterstained with $1 \mu \mathrm{g} / \mathrm{ml}$ DAPI (we omitted the incubation step with DNase I and anti-BrdU-alexa-647 antibody). A region gate for cell size and DNA content was applied to cells with intact DNA content. We also applied a DNA content double discrimination region gate (DAPI, area vs width). DNA content histograms were generated for the primary double discrimination region as well as the $\mathrm{CD} 31^{\text {high} /}$ $\mathrm{CD} 45^{\text {neg }}, \mathrm{CD} 31^{\text {low }} / \mathrm{CD} 45^{\text {high }}$, and $\mathrm{CD} 31^{\text {neg }} / \mathrm{CD} 45^{\text {neg }}$ cell populations.

\section{Statistical Analysis}

The effects of trebananib and an anti-Dll4 antibody as single agents on TAEC proliferation were compared with timematched vehicle-control groups using an unpaired two-tailed $t$-test. All statistical analyses were conducted using the GraphPad Prism 6 software (La Jolla, CA, USA).

Means and s.d. or s.e. were reported, and the differences were considered significant at $P$ values $<0.05$.

\section{RESULTS}

\section{Flow Cytometry-Based BrdUrd Uptake Analysis of CD31 ${ }^{\text {high }} /$ CD $5^{\text {neg }}$ Cells in Human Tumor Xenografts}

To measure TAEC proliferation in vivo, we developed a strategy of isolating low frequency $\mathrm{CD} 31^{\text {high }} / \mathrm{CD} 45^{\text {neg }}$ cells (TAEC) from a disaggregated tumor xenograft suspension comprising human tumor and mouse stromal cells and quantified their proliferation using BrdUrd uptake (approach outlined in Figure 1). First, we optimized the tissue processing methods that included tissue disruption, enzyme digestion, and cell fixation. We also determined that injecting mice with heparin (anticoagulant agent) before tissue collection increased the recovery of TAEC by approximately threefold, thus reducing the flow cytometry sample acquisition time and total event count (data not shown). As shown in Figures $2 \mathrm{a}$ and $\mathrm{b}$ (upper panel), cell surface staining with anti-CD31 and anti-CD45 antibodies successfully partitioned the $\mathrm{CD} 31^{\text {high }}$ and $\mathrm{CD} 31^{\text {neg }}$ cell populations in dissociated tumor xenografts (see Supplementary Figure 1a for primary gating and antibody controls). This antibody combination effectively excluded cells expressing $\mathrm{CD} 31^{\text {low }} / \mathrm{CD} 45^{\text {high }}$ (eg, tumor-associated macrophages) from the EC region gate. BrdUrd was delivered for $18 \mathrm{~h}$ by implanted osmotic minipump, as a single-bolus injection of BrdUrd showed minimal BrdUrd uptake in TAECs compared with other more highly proliferative tissues (eg, bone marrow, tumor cells). The need for a longer duration of BrdUrd administration may suggest that proliferating TAECs have a longer cell-cycle transit time (data not shown). As controls, ECs from adult mouse lung tissue provided a plentiful source of nonproliferating

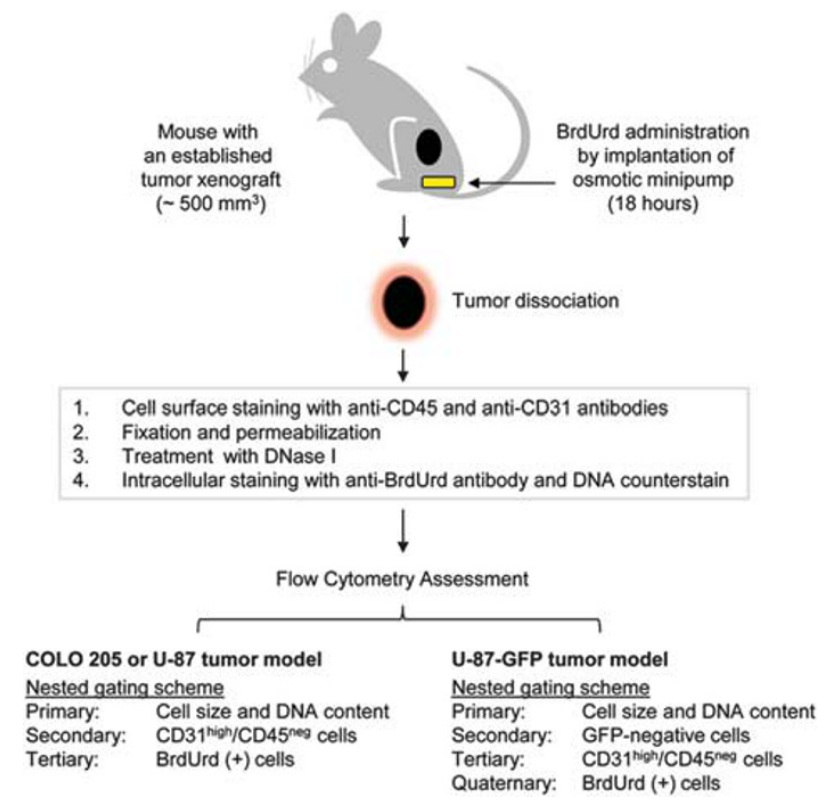

Figure 1 BrdUrd uptake analysis of CD31 high $/ C D 45^{\text {neg }}$ cells in human tumor xenografts. Outline of experimental approach for measuring BrdUrd uptake in CD31 high $/ C D 45^{\text {neg }}$ TAECs. Mice with established human tumor xenografts are administered BrdUrd $(3.3 \mathrm{mg} / \mathrm{ml}, 18 \mathrm{~h}$, flow rate of $8 \mu \mathrm{l}$ per hour) by implantation of osmotic minipump (yellow). Tumors are dissociated and stained with anti-CD31, anti-CD45, and anti-BrdUrd antibodies and counterstained with DNA dye. Cells are analyzed by flow cytometry using the indicated gating schemes (COLO 205 and U-87 (left column) or U-87-GFP (right column)).

$\mathrm{CD} 31^{\text {high }} / \mathrm{CD} 45^{\text {neg }}$ cells (noted by the lack of BrdUrd labeling), whereas animal-matched spleen tissue showed robust BrdUrd uptake (Supplementary Figure 2). The low frequency of TAECs (mean 0.7\% (COLO 205), mean 2\% (U-87)) present in xenograft tissue required $\sim 0.5-0.7 \times 10^{6}$ total events (primary gate) to establish an accurate proliferation labeling index. As shown in Figure 2 (lower panel), the BrdUrdpositive and negative population of $\mathrm{CD} 3 \mathrm{~h}^{\text {high }} / \mathrm{CD} 45^{\text {neg }}$ cells were well defined; the mean percentage of cells showing BrdUrd uptake was 13.1 (s.d. $\pm 2.2, n=3$ ) and $22.5 \%$ (s.d. $\pm 2.6, n=3$ ) for COLO 205 and U-87 tumor xenografts, respectively. DNA content analysis of TAECs was not performed due to the effects of DNase I treatment. However, cell cycle analysis (without BrdUrd staining) can be combined with cell surface staining to accurately determine TAEC DNA content by omitting the DNase I treatment step (Supplementary Figure 3). This method and gating scheme can also simultaneously monitor proliferation of $\mathrm{CD} 31^{\text {neg }} / \mathrm{CD} 45^{\text {neg }}$ cell population, although this cell population is heterogeneous and composed of a mixture of euploid mouse stromal cells and aneuploid human tumor cells (Supplementary Figure 3).

\section{In Vitro Characterization of COLO 205-Derived TAECs}

High-speed cell sorting was used to isolate TAEC from dissociated COLO 205 tumor xenografts, and 7-AAD dye was used to exclude dead cells (data not shown). The sorted 
a
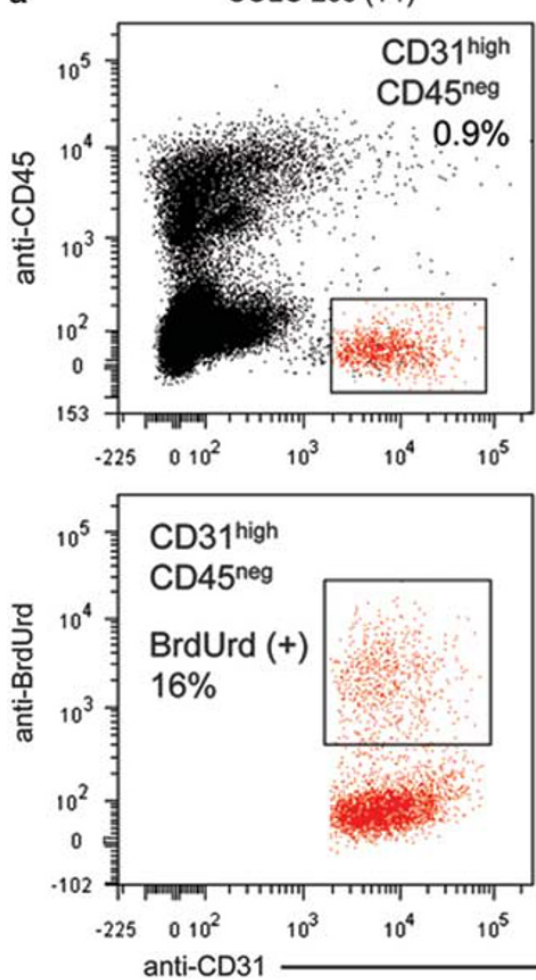

b
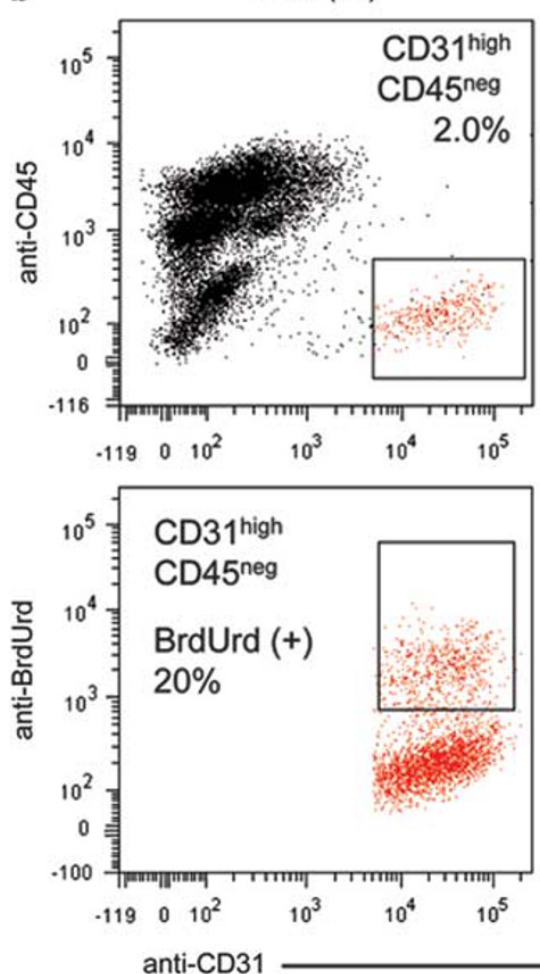

COLO $205($ T2)
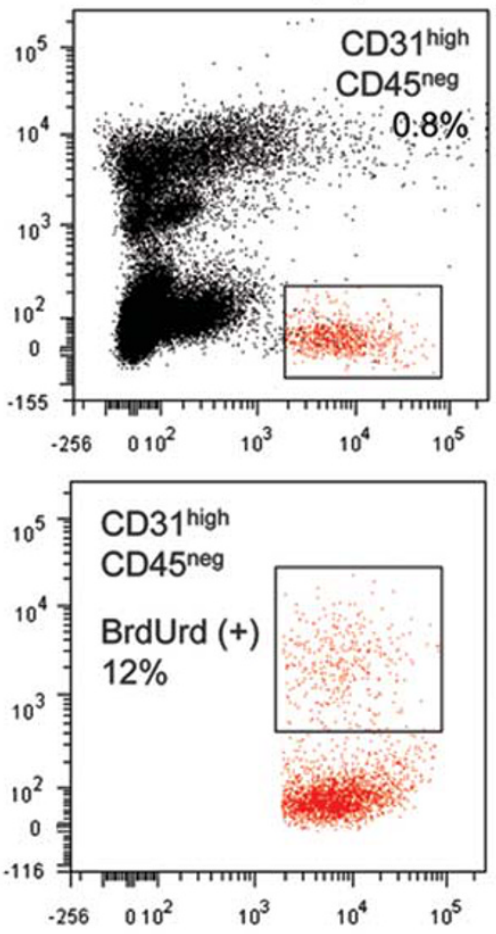
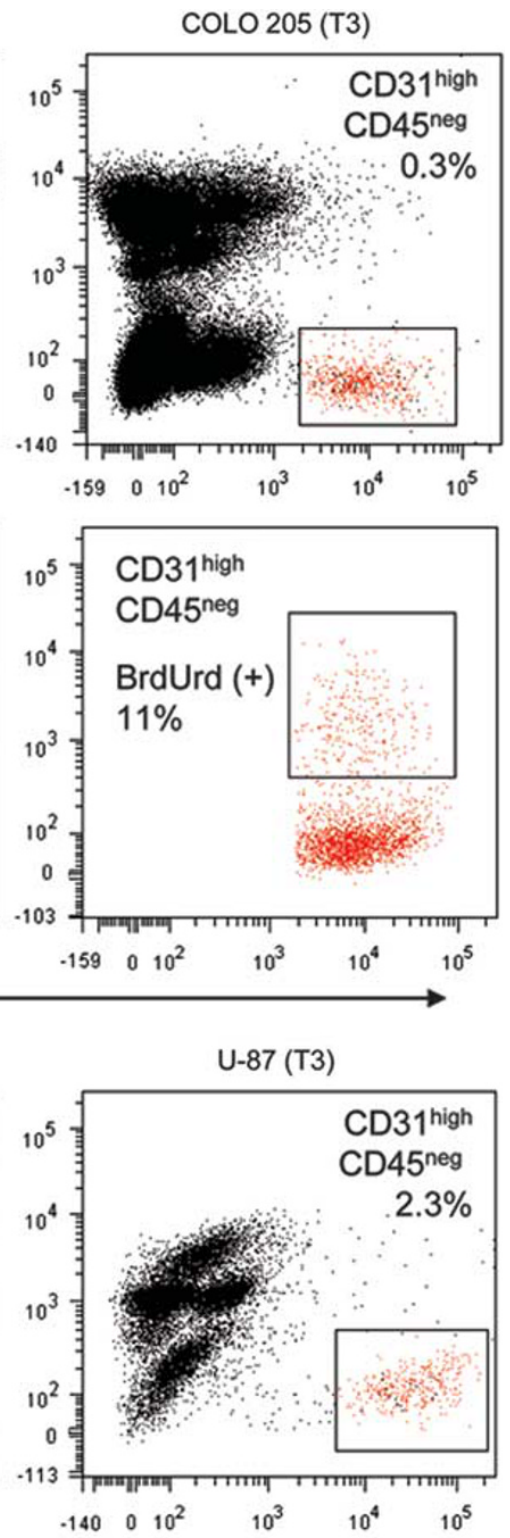

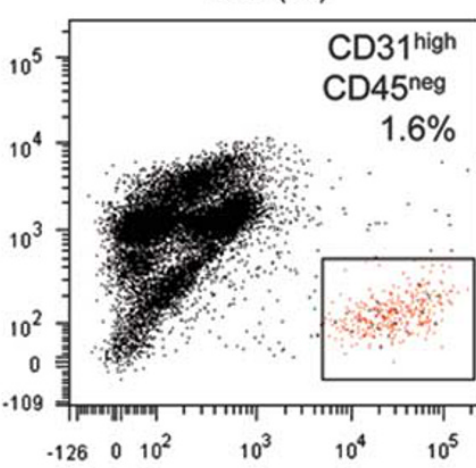

$\mathrm{U}-87(\mathrm{~T} 2)$
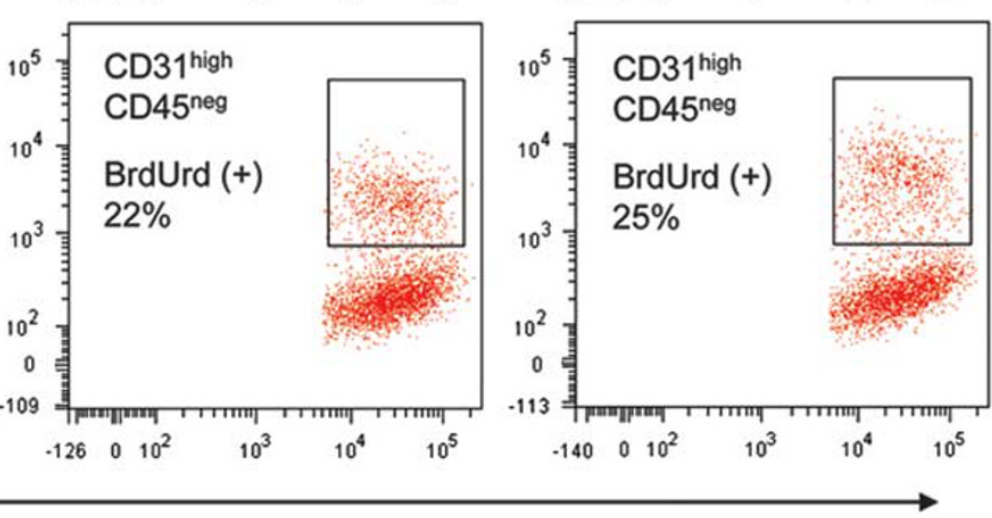

Figure 2 BrdUrd uptake analysis of TAECs in COLO 205 and U-87 human tumor xenografts. Flow cytometry analysis, dual parameter dot plots representing dissociated tumor xenograft cells stained with anti-CD31, anti-CD45, and anti-BrdUrd antibodies (see Supplementary Figure 1 for primary gating scheme and isotype controls). (a) $\mathrm{CD} 31^{\text {high }} / \mathrm{CD} 45^{\text {neg }}$ cells (red) were enumerated from COLO 205 human tumor xenografts ( $n=3$, frequency range $0.3-0.9 \%$, upper panel) and corresponding rate of proliferation (denoted as percentage of BrdUrd $(+)$, range $11-16 \%$, lower panel). $(\mathbf{b})$ CD $31^{\text {high }}$ / $\mathrm{CD} 45^{\text {neg }}$ cells $(r e d)$ were enumerated from U-87 human tumor xenografts $(n=3$, frequency range $1.6-2.3 \%$, upper panel) and corresponding rate of proliferation (denoted as percentage of BrdUrd (+), range $20-25 \%$, lower panel). 
viable CD $31^{\text {high }} / \mathrm{CD} 45^{\text {neg }}$ cells (sorted-TAECs) were collected into EC-defined growth media and cultured in preparation for EC analysis. As shown in Figure 3a, cultured sorted TAECs and control mouse SVR cells (SV40 large T antigen and $\mathrm{H}$-ras transformed ECs) expressed CD31 and Flk-1 (also known as VEGFR-2) at similar levels compared with isotype controls. The CD31 staining profile for the sorted TAECs showed a bimodal distribution, suggesting the population was heterogeneous, possibly due to unwanted stromal components (eg, fibroblasts) or phenotypic changes induced by removing TAECs from their microenvironment. ${ }^{18}$ We also tested early passage sorted TAECs for EC functional properties using an assay that measures cellular uptake of acetylated low-density lipoprotein. As previously reported, ECs in primary cell culture are distinguishable by their ability to endocytose Ac-LDL. ${ }^{22,28}$ First, sorted-TAECs were examined by laser scanning cytometry for their ability to take up fluorescently labeled DiI-Ac-LDL. As shown in Figure 3b, sorted TAECs selectively accumulated cytoplasmic Dil-Ac-LDL (lower image) compared with the non-acetylated Dil-LDL control (upper image). As a second measure, we evaluated the relative Dil-Ac-LDL uptake in four cell lines by flow cytometry. HUVECs showed the most intense DilAc-LDL labeling followed by sorted TAECs, SVR cells, and to a lesser degree in NIH-3T3 fibroblast control cells (Figure 3c). Together, these data indicate the $\mathrm{CD} 31^{\text {high }}$ / CD45 ${ }^{\text {neg }}$ cells isolated from COLO 205 tumor xenografts and cultured in vitro exhibit features consistent with an EC phenotype.

\section{BrdUrd Uptake Analysis of TAECs and GFP-expressing U-87 Tumor Cells in a Human Glioblastoma Tumor Xenograft Model}

A distinguishing feature of human glioblastoma tumors is microvascular proliferation and elevated secretion of proangiogenic factors such as VEGF. ${ }^{29-33} \mathrm{U}-87$ tumor xenografts are highly vascularized, making them ideal for investigating TAEC proliferation after treatment with agents that target angiogenesis. ${ }^{33}$ To improve our U-87 model, we established a GFP-expressing U-87 cell line that permitted accurate and concurrent BrdUrd analysis of both pure tumor and EC cell populations from the same xenograft sample (Figure 4). We modified the antibody staining procedure (substitution of anti-CD45-FITC with anti-CD45-PerCP) to circumvent issues with GFP and FITC occupying the same detector channel. We also changed the gating scheme to include GFPpositive (human tumor) and negative (mouse stromal) regions (Figure 1). The GFP-expressing tumor cells were clearly distinguishable from three primary mouse cell populations $\left(\mathrm{CD} 31^{\text {neg }} / \mathrm{CD} 45^{\text {neg }}, \quad \mathrm{CD} 31^{\text {high }} / \mathrm{CD} 45^{\text {neg }}\right.$, and $\mathrm{CD} 31^{\text {neg }} /$ $\mathrm{CD} 45^{\text {high }}$ ) (Figure $4 \mathrm{a}$ ). The frequency of $\mathrm{CD} 31^{\text {high }} / \mathrm{CD} 45^{\text {neg }}$ cells in U-87-GFP tumor xenografts using this additional gating parameter was similar to U-87 parental tumors. The mean percentage of BrdUrd-positive TAEC and U-87-GFP tumor cells from three matched tumors was 25.3 (s.d. \pm 4.2 , $n=3$ ) and $36 \%$ (s.d. $\pm 2.4, n=3$ ), respectively (Figure $4 \mathrm{~b}$ ). These data demonstrate the GFP-tag enables identification of the tumor cell population that was previously masked in the U-87 parental tumor xenografts by a sizable population of $\mathrm{CD} 31^{\text {neg }} / \mathrm{CD} 45^{\text {neg }}$ mouse cells (Supplementary Figure 3 ).

Next, we performed immunohistochemical examination of U-87-GFP tumors with anti-CD31 and anti-BrdUrd antibodies to confirm TAEC proliferation. As shown in Figures $4 \mathrm{c}$, a representative tumor section was immunoreactive with CD31 labeled microvessels, where a subset of EC nuclei showed robust BrdUrd labeling (upper panel). Red blood cells were also detectable in the space bound by CD31 labeling. Importantly, the EC BrdUrd nuclear morphology features were distinct from human tumor cell nuclei (Figure 4c, lower panel). ${ }^{34,35}$ Individual BrdUrd-negative EC nuclei were difficult to identify; therefore, a labeling index was not determined. In addition, BrdUrd labeling variation was evident in different regions of the tumor due to necrosis and/or hypocellularity (data not shown). Together, these data indicate that both flow cytometry- and imaging-based analysis of U-87-GFP tumors detect robust BrdUrd labeling in a subset of TAECs.

\section{Angiopoietin-Tie2 and DII4-Notch Signaling Inhibition Has Opposing Effects on TAEC Proliferation in Human Tumor Xenografts}

Having established the basal proliferation level and endothelial features of $\mathrm{CD} 31^{\text {high }} / \mathrm{CD} 45^{\text {neg }}$ cell population from dissociated human tumor xenografts, we next evaluated the effects of trebananib, a peptide-Fc fusion protein that targets Ang-1 and Ang-2, on TAEC proliferation. Mice with established COLO 205 tumor xenografts were treated with a single injection of trebananib $(15 \mathrm{mg} / \mathrm{kg}$, s.c.) or vehicle alone as a control. After $48 \mathrm{~h}$, the tumors were processed and analyzed by flow cytometry using the scheme outlined in Figure 1. As shown in Figures $5 a$ and b, trebananib treatment significantly inhibited the proliferation of TAEC (mean decrease of BrdUrd uptake $89.6 \%, P=0.0002$ ). The mean percentage of BrdUrd uptake for TAEC from trebananib- and vehicle-treated groups was 1.3 (s.d. $\pm 0.4, n=4$ ) and $12.9 \%$ (s.d. $\pm 2.8, n=4$ ), respectively. Treatment with trebananib at lower doses $(6 \mathrm{mg} / \mathrm{kg})$ also inhibits TAEC proliferation in the COLO 205 tumor xenograft model. ${ }^{11}$

To characterize the effects of inhibiting angiopoietin-Tie2 or Dll4-Notch signaling in a highly vascularized tumor model, mice with established U-87-GFP tumors were treated with a single injection of either trebananib $(5.6 \mathrm{mg} / \mathrm{kg}$, s.c.) or anti-Dll4 mouse monoclonal antibody $(12 \mathrm{mg} / \mathrm{kg}$, i.p.). U-87-GFP tumors were collected from mice treated with either anti-Dll4 antibody or trebananib at either $24 \mathrm{~h}$ (antiDll4 antibody) or $48 \mathrm{~h}$ (trebananib) along with time-matched vehicle-treated controls. Next, the tumors were processed using the scheme outlined in Figure 1. Trebananib treatment significantly inhibited proliferation of TAECs (mean decrease of BrdUrd uptake 54.5\%, $P=0.002$ ) (Figure 6a). The mean 
a
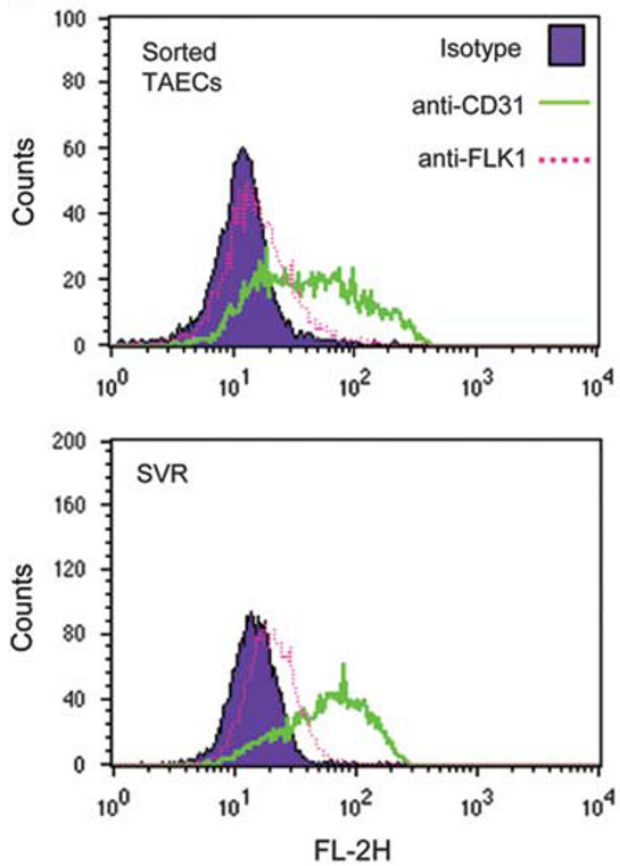

b
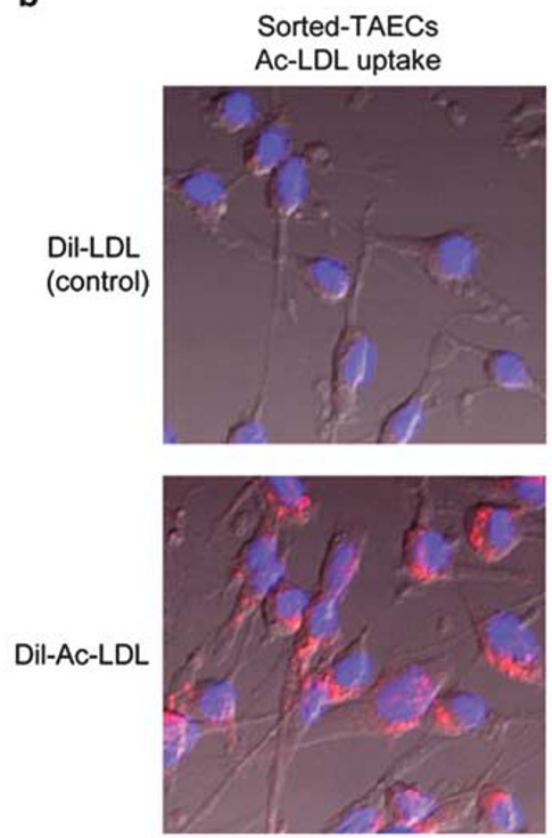

C

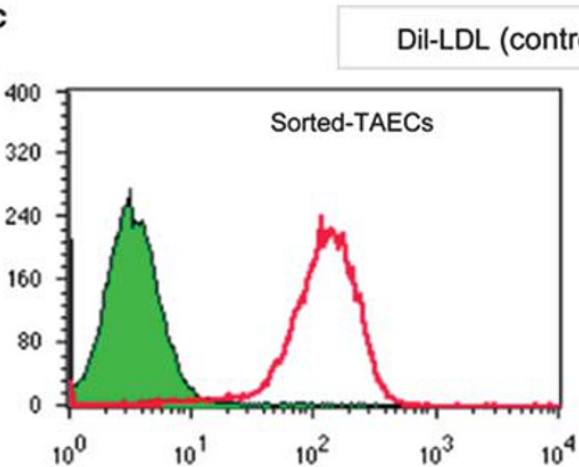

FL-2H

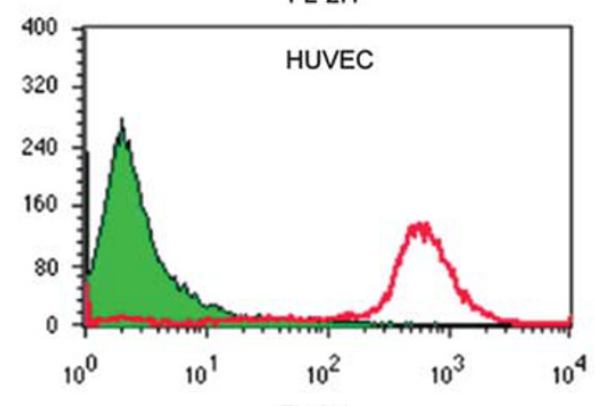

$\mathrm{FL}-2 \mathrm{H}$

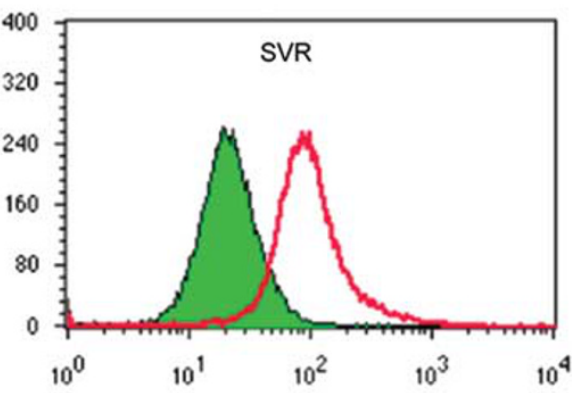

FL-2H

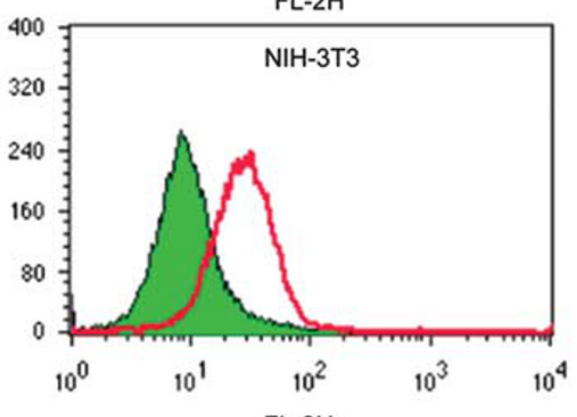

$\mathrm{FL}-2 \mathrm{H}$

Figure 3 In vitro characterization of sorted CD31 high $/$ CD45 ${ }^{\text {neg }}$ cells (sorted TAECs) isolated from COLO 205 human tumor xenografts. (a) Flow cytometry analysis, histogram overlays of early passage sorted TAECs and mouse SVR cells (positive control) stained with EC-lineage markers (anti-CD31 (green), anti-Flk-1 (pink)) and isotype antibody lgG2a (solid purple, control). (b) Representative fluorescence images of early passage sorted TAECs cultured for $4 \mathrm{~h}$ in the presence of fluorochrome-conjugated (Dil) LDL (nonacetylated LDL, control) or acetylated LDL (Ac-LDL). Detection of Dil fluorochrome (red) and DAPI (blue) was performed by laser scanning cytometry. (c) Flow cytometry analysis, histograms of HUVECs, sorted TAECs, SVR cells, and NIH-3T3 cells cultured for $4 \mathrm{~h}$ in the presence of Dil-LDL (green, control) or Dil-Ac-LDL (red).

percentage of BrdUrd uptake for TAEC trebananib and vehicle-control groups were 11.9 (s.e. $\pm 3.3, n=6$ ) and $26.1 \%$ (s.e. $\pm 0.9, n=6$ ), respectively. One mouse treated with trebananib showed no effect on TAEC proliferation (perhaps due to low drug exposure). In contrast to the antiproliferative effects of trebananib, treatment with an anti-Dll4 antibody 
a
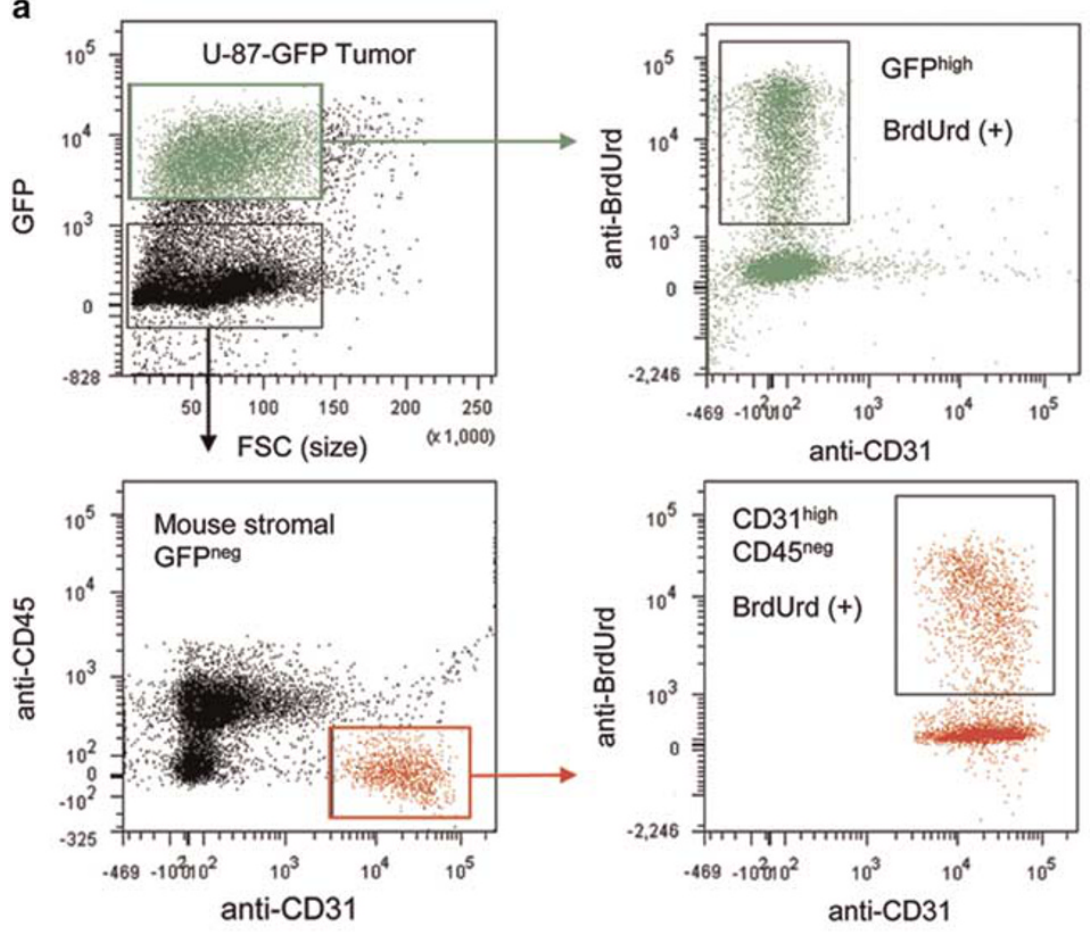

b

U-87-GFP (T1)

U-87-GFP (T2)

U-87-GFP (T3)
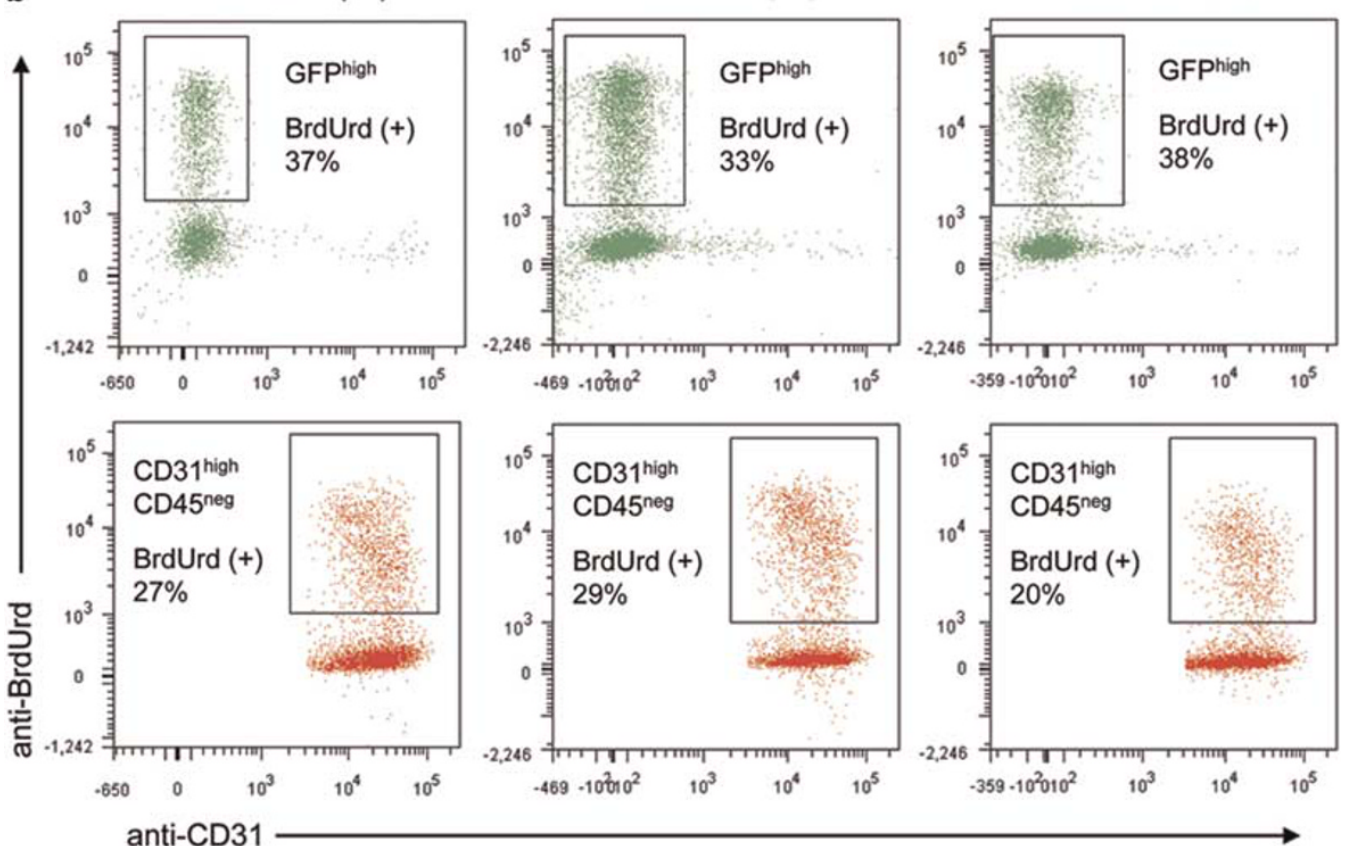

Figure 4 BrdUrd uptake analysis of TAECs and GFP-expressing tumor cells in U-87 human tumor xenografts. (a, b) Flow cytometry analysis, dual parameter dot plots representing tumor xenograft cells stained with anti-CD31, anti-CD45, and anti-BrdUrd antibodies. (a) Gated regions were set on GFP-positive (green, human tumor cells) and GFP-negative (black, mouse cells) cell populations. Additional gated region set on the CD31 ${ }^{\text {high }} / \mathrm{CD} 45^{\text {neg }}$ cell population (red). (b) BrdUrd uptake for TAECs and U-87-GFP tumor cells $(n=3)$ were determined with respective percentage of BrdUrd $(+)$ population ranges of $20-29 \%$ (lower panel) and 33-38\% (upper panel). (c) IHC analysis of U-87-GFP tumor co-labeled with anti-CD31 and anti-BrdUrd antibodies. CD31-labeled microvascular structures (blue) and BrdUrd-labeled nuclei (brown). Image gallery of representative BrdUrd-labeled CD31 nuclei (red arrows) with distinct nuclear morphology compared with BrdUrd-labeled tumor nuclei (lower panel). Scale bar $=100 \mu \mathrm{m}$ (upper panel),

enlargements of representative views are shown in lower panel. 


\section{Representative Field Level Image of U-87-GFP Tumor} Double label: Anti-CD31 (blue), Anti-BrdUrd (brown)
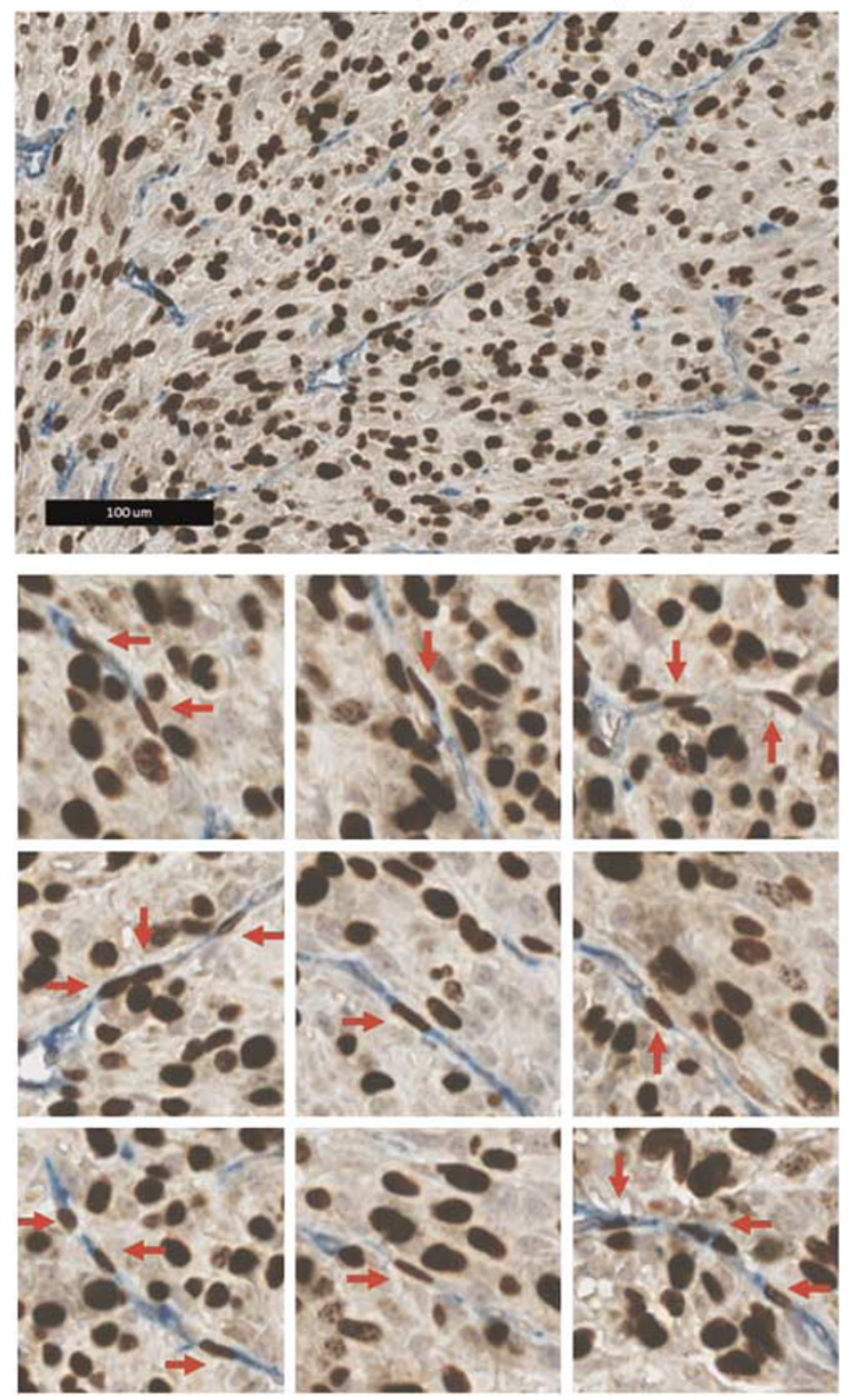

Figure 4 Continued.

induced hyperproliferation of TAECs. As shown in Figure 6b, an anti-Dll4 antibody significantly increased proliferation of TAECs (mean increase of BrdUrd uptake 52.5\%, $P=0.0007$ ). The mean percentage of BrdUrd uptake for an anti-Dll4 antibody and vehicle-control groups was 41.7 (s.e. \pm 2.7 , $n=6$ ) and $27.1 \%$ (s.e. $\pm 1.3, n=6$ ), respectively. Taken together, our results indicate that the TAEC from tumor xenografts respond to treatment with antiangiogenic agents, and that selective blocking of angiopoietin-Tie2 or Dll4Notch signaling has distinct effects on TAEC proliferation.

\section{DISCUSSION}

In this report, we describe a flow cytometry-based method designed to accurately measure BrdUrd uptake in TAECs from dissociated human tumor xenografts. Our study demonstrates the utility of this method for cancer drug discovery by evaluating the effects of two antiangiogenic agents (trebananib and an anti-Dll4 antibody) on TAEC proliferation from human tumor xenografts. The main limitations for traditional imaging-based detection of TAEC proliferation include the following: (1) assays are low throughput and labor-intensive; (2) technical challenges in EC nuclei detection due to nuclei morphology (elongated thin oval shape); (3) histology only includes a slice or small portion of a tumor rather than whole tumor measurement; and (4) proliferation labeling index is based on limited cell number due to the low frequency of TAECs. To overcome these limitations, we developed an alternative higher throughput flow cytometrybased TAEC proliferation assay. In developing our assay, we utilized normal mouse lung tissue (a plentiful source of ECs) and human tumor xenografts to optimize tissue processing, dissociation, and cell surface staining protocols. As a first step, we found that establishing flow cytometry instrument settings (PMTs and compensation) using mouse lung tissue (or heart tissue) is critical to guide detection of low frequency TAEC population from human tumor xenografts. A number of factors may influence the frequency of TAEC detection using our method including tumor size, tumor type, tumor vascular density, level of tumor necrosis, and efficiency of tumor dissociation. For instance, increased tumor vascular density (a hallmark of glioblastomas) may explain the higher frequency of TAECs observed from U-87 tumor xenografts compared with COLO 205 tumor xenografts. Similarly, the basal proliferation labeling index for TAECs was noticeably higher in U-87 tumor xenografts compared with COLO 205 tumor xenografts, possibly due to the elevated expression of human VEGF in U-87 tumor xenografts. ${ }^{12}$ We also provided evidence that short-term culture of sorted TAECs isolated from COLO 205 tumor xenografts exhibited features consistent with an EC phenotype: cell surface expression of CD31 and live-cell labeling with DiI-Ac-LDL. In addition to $\mathrm{CD} 31$ staining, the specificity of $\mathrm{CD} 31^{\text {high }} / \mathrm{CD} 45^{\text {neg }}$ cell population was further authenticated by competing away an anti-CD31-PE antibody signal using excess unlabeled CD31 antibody and staining positive with an EC-specific antibody, CD144 (also known as VE-cadherin, vascular endothelial) (data not shown). We refined our method by constitutively expressing GFP in U-87 tumor cells, thus allowing for parallel assessment of BrdUrd uptake in TAECs and tumor cells as well as circumventing the need for additional tumor-specific antibody markers. Together, these results indicate our method is robust, adaptable, and has several key advantages over imaging-based approaches used to measure TAEC proliferation. Our approach using tissue dissociation destroys the architecture and vasculature of the tumor, requiring parallel imaging studies to assess vessel shape and size as well as vessel network integrity and density in the tumor microenvironment.

Drugs that target angiogenesis through the inhibition of the VEGF-pathway are used to treat a subset of human 


\section{COLO 205 tumor, CD31 ${ }^{\text {high }} /$ CD $45^{\text {neg }}$ cell population}
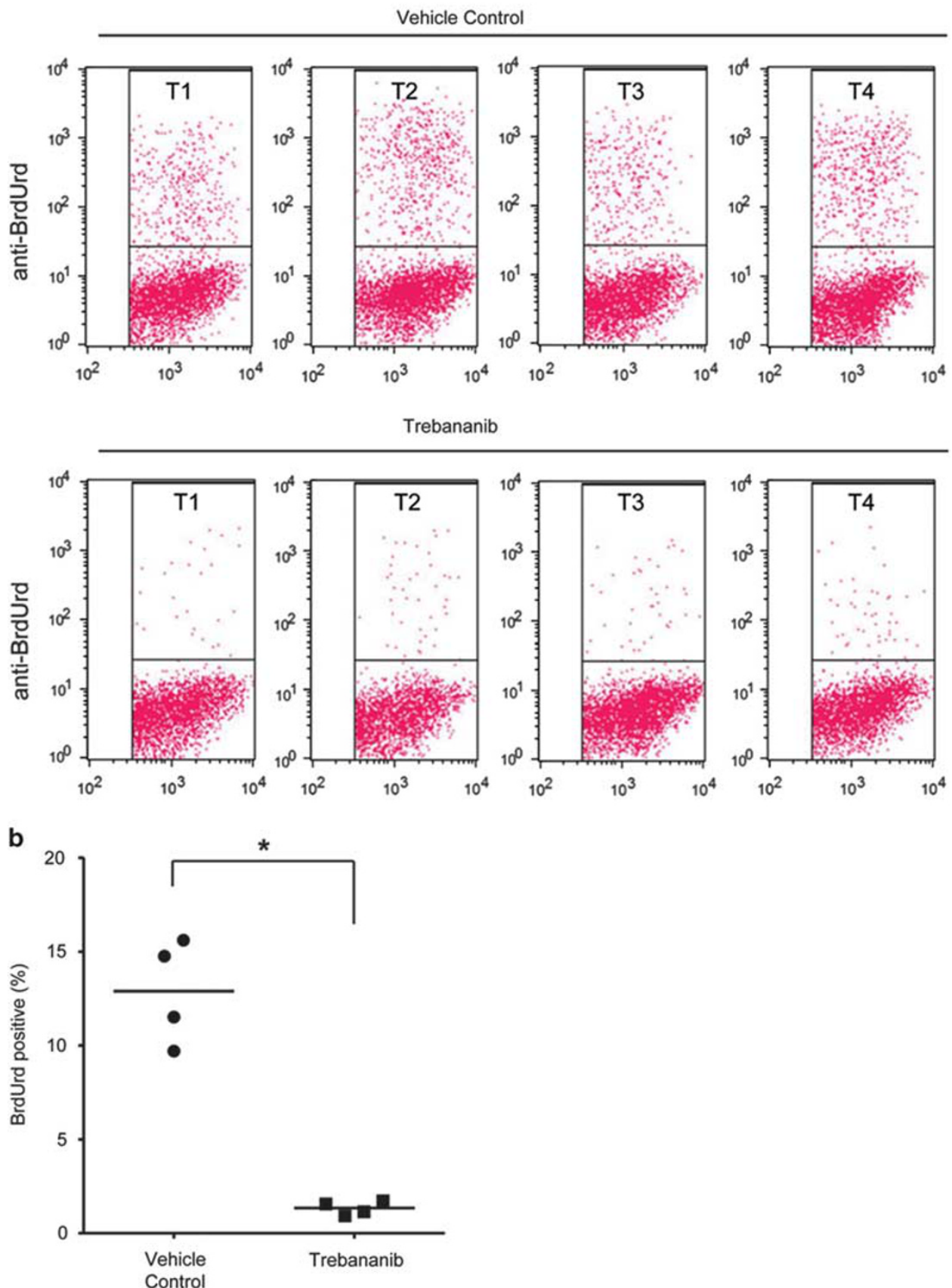

Figure 5 Trebananib inhibits proliferation of TAECs in COLO 205 human tumor xenografts. Mice with established COLO 205 tumor xenografts were treated with a single injection of trebananib at $15 \mathrm{mg} / \mathrm{kg}$ (s.c.) or vehicle alone. Tumors were collected $48 \mathrm{~h}$ after treatment and processed for flow cytometry as outlined in Figures 1 and 3. (a) Flow cytometry analysis, dual parameter dot plots denoting BrdUrd-positive and negative region gates for CD31 $1^{\text {high }} / C D 45^{\text {neg }}$ cells ( $n=4$ per treatment group). (b) Quantitation of BrdUrd uptake in CD31 ${ }^{\text {high }} / C D 45^{\text {neg }}$ cells. Plot represents BrdUrd uptake (percentage BrdUrd $(+)$ ) indicated as the mean between treatment groups. Statistically significant inhibition of BrdUrd uptake compared with vehiclecontrol group is denoted by an asterisk $(P=0.0002)$.

cancers and ocular diseases. ${ }^{4}$ Other angiogenesis signaling molecules implicated in blood vessel development and differentiation also represent potential therapeutic targets, including angiopoietins and Dll4. ${ }^{4-6}$ Recently, we reported selective inhibition of Ang-2 (but not Ang-1) was responsible for blocking both TAEC proliferation in tumor xenografts and VEGF-mediated rat corneal angiogenesis. ${ }^{7,11}$ Our current study highlights that dual inhibition of Ang-1 and Ang-2 


\section{a U-87-GFP tumor, CD $31^{\text {high }} / \mathrm{CD} 45^{\text {neg }}$ cell population}
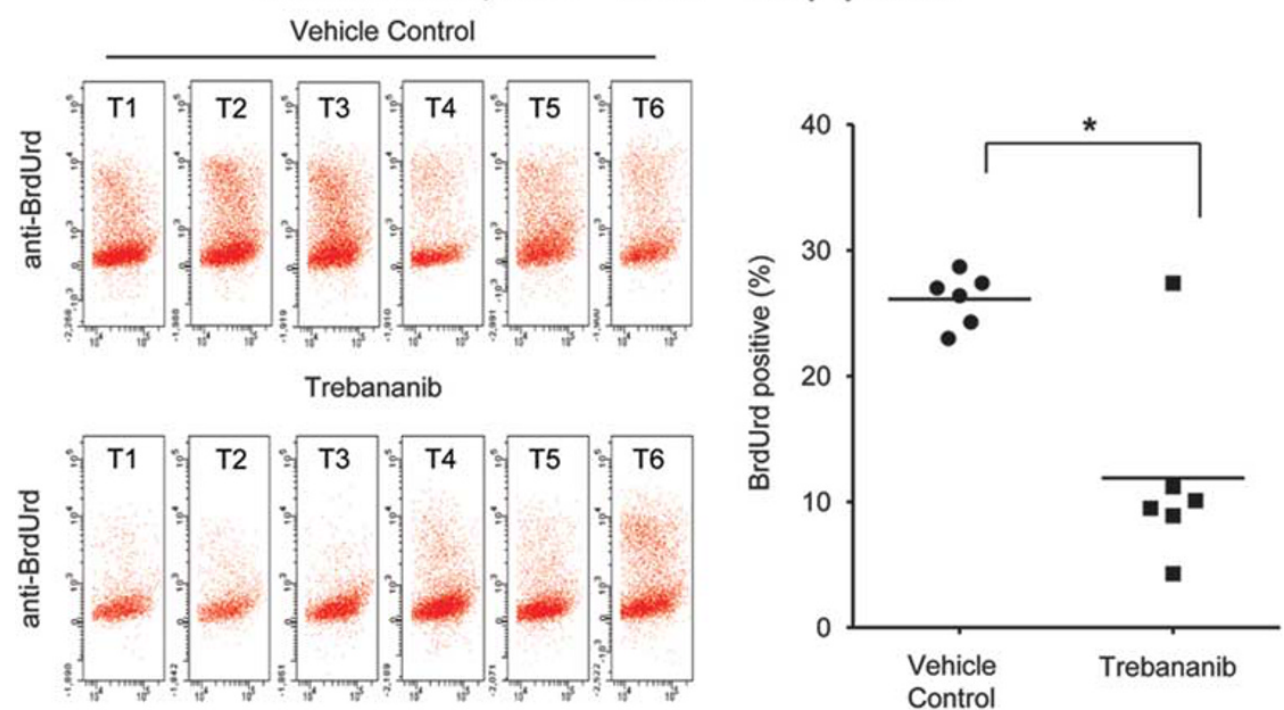

b U-87-GFP tumor, CD $31^{\text {high }} / \mathrm{CD} 45^{\text {neg }}$ cell population
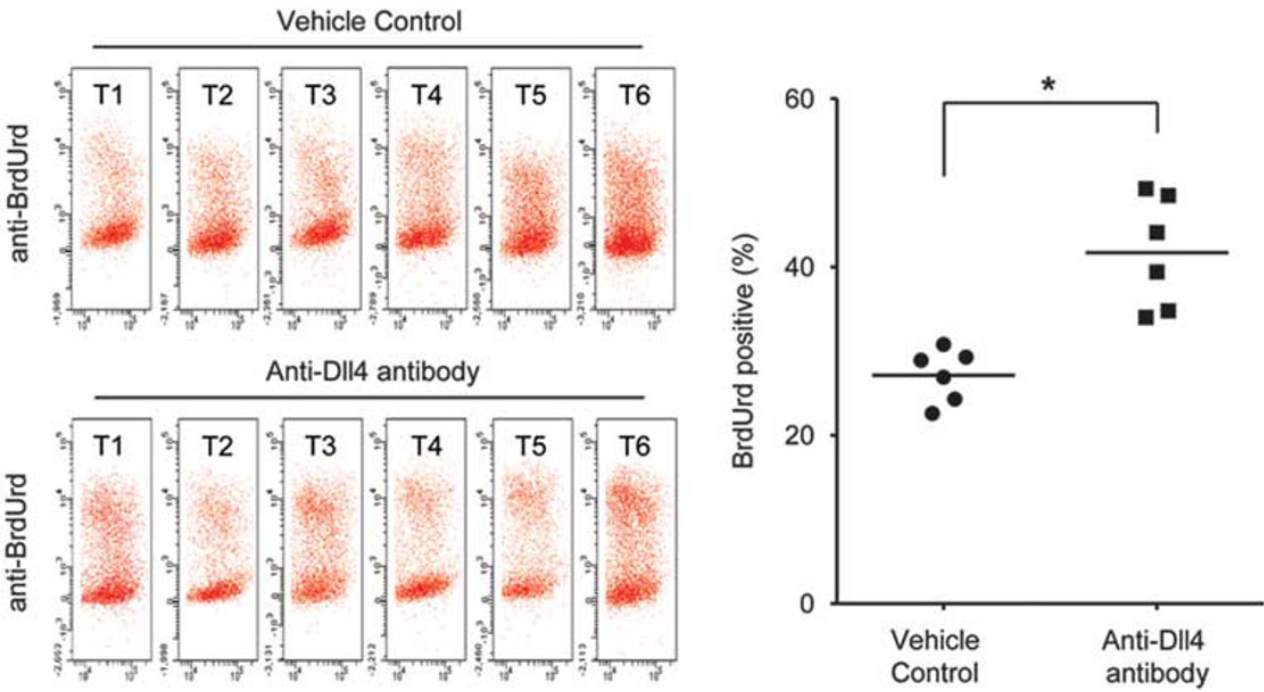

Figure 6 Trebananib and DII4 antibodies have opposing effects on proliferation of TAECs in U-87-GFP human tumor xenografts. Mice with established U-87-GFP tumor xenografts were treated with a single injection of trebananib (5.6 mg/kg, s.c.), anti-Dll4 mouse monoclonal antibody (12 mg/kg, i.p.), or vehicle control (equivalent amount of human Fc or mouse IgG, respectively). Tumors were collected after $24 \mathrm{~h}$ (anti-DIl4 antibody group, $n=6$ ) and $48 \mathrm{~h}$ (trebananib group, $n=6$ ) along with corresponding time-matched vehicle-controls $(n=6)$. Tumors were collected after treatment and processed for flow cytometry as outlined in Figures 1 and 4. (a) Trebananib or (b) anti-DII4 antibody, dual parameter dot plots denoting BrdUrd-positive and negative region gates for individual tumor $\mathrm{CD} 31^{\text {high }} / \mathrm{CD} 45^{\text {neg }}$ cell population and corresponding quantification of BrdUrd uptake. Plots represent BrdUrd uptake (percentage BrdUrd $(+)$ ) indicated as the mean between treatment groups. Statistically significant decrease or increase of BrdUrd uptake compared with vehicle-control group is denoted by an asterisk (trebananib, $P=0.002$; anti-DIl4 antibody, $P=0.0007$ ).

with trebananib blocks TAEC proliferation; the extent of BrdUrd inhibition with trebananib was more pronounced on TAECs from COLO 205 vs U-87-GFP tumor xenografts (percentage of BrdUrd inhibition: 89.6 vs 54.5\%, respectively). One possible explanation for why trebananib is less effective at inhibiting TAEC proliferation in U-87-GFP model is the proangiogenic signaling threshold may be higher due to higher levels of VEGF expression by the U87-GFP cells compared with the COLO 205 cells. In support of this hypothesis, human VEGF expression is fourfold higher in U-87 tumor xenografts compared with COLO 205 tumor xenografts. ${ }^{12}$ Further studies could explore whether lowering the level of human VEGF in U-87-GFP tumor xenografts (through gene-silencing or antibody sequestration of human 
VEGF) would reduce the basal rate of TAEC proliferation, thus permitting more complete suppression of BrdUrd uptake by trebananib.

In contrast to blocking angiopoietin signaling with trebananib, antagonism of Dll4 signaling with an anti-Dll4 antibody induced rapid (within $24 \mathrm{~h}$ ) hyperproliferation of TAECs in U-87-GFP tumor xenografts. Our findings are consistent with the previous observations that inhibition of Dll4 increased TAEC number, which results in excessive angiogenic sprouting and branching with disordered tumor vascular geometry. ${ }^{13-17}$ There is growing interest in combining antiangiogenic agents in an effort to enhance tumor cell starvation and to overcome issues of resistance. ${ }^{36}$ One intriguing approach would be to simultaneously suppress both angiopoietin-Tie2 and Dll4-Notch signaling pathways; this may enhance the suppression of functional angiogenesis within the tumor microenvironment. To test this strategy, we combined trebananib with an anti-Dll4 antibody and established that concurrent inhibition of both signaling pathways leads to enhanced anti-angiogenic activity and efficacy in preclinical human tumor xenograft models ${ }^{37}$ (manuscript in preparation). In summary, we have developed an innovative flow cytometry-based method capable of measuring TAEC proliferation from human tumor xenografts. This approach offers the opportunity to rapidly evaluate the effects of antiangiogenic agents on TAEC proliferation in vivo. To that end, we provide preclinical evidence that trebananib and anti-Dll4 antibody had opposing effects on TAEC proliferation, highlighting their distinct modes of action. Lastly, this method is likely adaptable to other tumor types and models such as patient-derived tumor xenografts or genetically engineered mouse models of human cancer.

Supplementary Information accompanies the paper on the Laboratory Investigation website (http://www.laboratoryinvestigation.org)

\section{ACKNOWLEDGMENTS}

We thank their Angiogenesis Team colleagues in Oncology, Pathology, and Clinical Immunology for their contributions, and Kenneth Brasel and Steve Coats for their early insights and encouragement. We also thank Gloria Juan, Robert Loberg, Sean Caenepeel, and Tara Arvedson for their critical reading of this manuscript and Stephanie Matyas for excellent technical assistance. This manuscript is dedicated to the memory of our colleague Beth Ziegler, a significant contributor to this work and multiple cancer pharmacology programs at Amgen.

\section{DISCLOSURE/CONFLICT OF INTEREST}

All authors are current or former employees of Amgen Inc.

1. Folkman J. Angiogenesis in cancer, vascular rheumatoid and other disease. Nat Med 1995;1:27-31.

2. Yancopoulos GD, Davis S, Gale NW, et al. Vascular-specific growth factors and blood vessel formation. Nature 2000;407:242-248.

3. Folkman J. Angiogenesis: an organizing principle for drug discovery? Nat Rev Drug Discov 2007;6:273-286.
4. Carmeliet P, Jain RK. Molecular mechanisms and clinical applications of angiogenesis. Nature 2011;473:298-307.

5. Weis SM, Cheresh DA. Tumor angiogenesis: molecular pathways and therapeutic targets. Nat Med 2011;17:1359-1370.

6. Huang $\mathrm{H}$, Bhat $\mathrm{A}$, Woodnutt $\mathrm{G}$, et al. Targeting the ANGPT-TIE2 pathway in malignancy. Nat Rev Cancer 2010;10:575-585.

7. Oliner J, Min H, Leal J, et al. Suppression of angiogenesis and tumor growth by selective inhibition of angiopoietin-2. Cancer Cell 2004;6:507-516.

8. Mita AC, Takimoto CH, Mita M, et al. Phase 1 study of AMG 386, a selective angiopoietin 1/2-neutralizing peptibody, in combination with chemotherapy in adults with advanced solid tumors. Clin Cancer Res 2010;16:3044-3056.

9. Herbst RS, Hong D, Chap L, et al. Safety, pharmacokinetics, and antitumor activity of AMG 386, a selective angiopoietin inhibitor, in adult patients with advanced solid tumors. J Clin Oncol 2009;27: 3557-3565.

10. Karlan BY, Oza AM, Richardson GE, et al. Randomized, double-blind, placebo-controlled phase II study of AMG 386 combined with weekly paclitaxel in patients with recurrent ovarian cancer. J Clin Oncol 2012;30:362-371.

11. Coxon A, Bready J, Min H, et al. Context-dependent role of angiopoietin-1 inhibition in the suppression of angiogenesis and tumor growth: implications for AMG 386, an angiopoietin-1/2neutralizing peptibody. Mol Cancer Ther 2010;9:2641-2651.

12. Hashizume $\mathrm{H}$, Falcon $B L$, Kuroda $T$, et al. Complementary actions of inhibitors of Angiopoietin-2 and VEGF on tumor angiogenesis and growth. Cancer Res 2010;70:2213-2223.

13. Ridgway J, Zhang G, Wu Y, et al. Inhibition of Dll4 signaling inhibits tumour growth by deregulating angiogenesis. Nature 2006;444: 1083-1087.

14. Noguera-Troise I, Daly C, Papadopoulos NJ, et al. Blockade of DII4 inhibits tumour growth by promoting non-productive angiogenesis. Nature 2006;444:1032-1037.

15. Li JL, Sainson RCA, Shi W, et al. Delta-like 4 notch ligand regulates tumor angiogenesis, improves tumor vascular function, and promotes tumor growth in vivo. Cancer Res 2007;67:11244-11253.

16. Jenkins DW, Ross S, Veldman-Jones $M$, et al. MEDI0639: A novel therapeutic antibody targeting DIl4 modulates endothelial cell function and angiogenesis in vivo. Mol Cancer Ther 2012;11: 1650-1660.

17. Yen WC, Fischer MM, Hynes M, et al. Anti-DLL4 has broad spectrum activity in pancreatic cancer dependent on targeting DLL4-Notch signaling in both tumor and vasculature cells. Clin Cancer Res 2012;18:5374-5386.

18. van Beijnum JR, Rousch $M$, Castermans $K$, et al. Isolation of endothelial cells from fresh tissues. Nat Prot 2008;3:1085-1091.

19. van Beijnum JR, van der Linden E, Griffioen AW, et al. Angiogenic profiling and comparison of immortalized endothelial cells for functional genomics. Exp Cell Res 2008;314:264-272.

20. St. Croix B, Rago C, Velculescu V, et al. Gene expression in human tumor endothelium. Science 2000:289:1197-1202.

21. Akino T, Hida K, Hida Y, et al. Cytogenetic Abnormalities of TumorAssociated Endothelial Cells in Human Malignant Tumors. Am J Pathol 2009:175:2657-2667.

22. Voyta JC, Via DP, Butterfield CE, et al. Identification and isolation of endothelial cells based on their increased uptake of acetylated-low density lipoprotein. J Cell Biol 1984;99:2034-2040.

23. Naschberger E, Schellerer VS, Rau T, et al. In: Ian AC (ed). Cancer Cell Culture Methods in Molecular Biology, $2^{\text {nd }}$ edn. Springer Science \& Business Media, LLC, 2011.

24. Khan SS, Solomon MA, McCoy JP. Detection of circulating endothelial cells and endothelial progenitor cells by flow cytometry. Cytometry Part B (Clin Cytometry) 2005;64B:1-8.

25. Ezaki $T$, Baluk $P$, Thurston $G$, et al. Time Course of endothelial cell proliferation and microvascular remodeling in chronic inflammation. Am J Pathol 2001;158:2043-2055.

26. Mancuso $P$, Antoniotti $P$, Quarna J, et al. Validation of a standardized method for enumerating circulating endothelial cells and progenitors: Flow cytometry and molecular and ultrastructural analyses. Clin Cancer Res 2009;15:267-273.

27. Payton M, Chung G, Yakowec P, et al. Discovery and evaluation of dual CDK1 and CDK2 inhibitors. Cancer Res 2006;66:4299-4308. 
28. Modzelewski RA, Davies $\mathrm{P}$, Watkins SC, et al. Isolation and identification of fresh tumor-derived endothelial cells from a murine RIF-1 fibrosarcoma. Cancer Res 1994;54:336-339.

29. Hormigo A, Ding BS, Rafii S. A target for antiangiogenic therapy: Vascular endothelium derived from glioblastoma. PNAS 2011;108: 4271-4272.

30. Wang R, Chadalavada K, Wilshire J, et al. Glioblastoma stem-like cells give rise to tumour endothelium. Nature 2010;468:829-833.

31. Ricci-Vitiani $L$, Pallini $R$, Biffoni $M$, et al. Tumour vascularization via endothelial differentiation of glioblastoma stem-like cells. Nature 2010;468:824-828.

32. Vajkoczy P, Farhadi M, Gaumann A, et al. Microtumor growth initiates angiogenic sprouting with simultaneous expression of VEGF, VEGF receptor-2, and angiopoietin-2. J Clin Invest 2002;109: 777-785.
33. Wachsberger PR, Burd R, Cardi C, et al. VEGF Trap in combination with radiotherapy improves tumor control in U87 glioblastoma. Int. J. Radiation Oncology Biol Phys 2007;67:1526-1537.

34. Tovari J, Gilly R, Raso E, et al. Recombinant human erythropoietin $\alpha$ targets intratumoral blood vessels, improving chemotherapy in human xenograft models. Cancer Res 2005;65:7186-7193.

35. Denekamp J, Hobson B. Endothelial-cell proliferation in experimental tumours. Brit J Cancer 1982;46:711-720.

36. Sennino B, McDonald DM. Controlling escape from angiogenesis inhibitors. Nature Rev Cancer 2013;12:699-708.

37. Coxon A, Kaplan-Lefko P, Kaufman S, et al. Inhibition of angiopoietin and Dll4 signaling in the tumor vasculature leads to increased efficacy in mouse tumor xenograft models. Proceedings: AACR 103rd Annual Meeting 2012) Available from http://cancerres.aacrjournals.org/cgi/ content/meeting_abstract/72/8_MeetingAbstracts/LB-311. 